\title{
Disperse Amphiphilic Submicron Particles as Non-Covalent Supports for Cationic Homogeneous Catalysts
}

\author{
Rafaël Sablong, , Jarl Ivar van der Vlugt, ${ }^{a}$ Ralf Thomann, ${ }^{\mathrm{b}}$ Stefan Mecking, ${ }^{\mathrm{c}, *}$ \\ Dieter $\operatorname{Vog}^{\mathrm{a}}{ }^{\mathrm{*}}$,
}

a Schuit Institute of Catalysis, Laboratory of Homogeneous Catalysis, Eindhoven University of Technology, PO Box 513, 5600 MB Eindhoven, The Netherlands Fax: (+31)-40-245-5054, e-mail: d.vogt@tue.nl

b Institute for Macromolecular Chemistry and Freiburg, Materials Research Center, Albert-Ludwigs-University Freiburg, Stefan-Meier-Str. 31, 79104 Freiburg, Germany

Department of Chemistry, University of Konstanz, Universitätsstr. 10, 8457 Konstanz, Germany

Fax: (+49)-7531-88-5152, e-mail: stefan.mecking@uni-konstanz.de

\begin{abstract}
A simple method for the effective immobilization of homogeneous catalysts on polystyrene colloids via non-covalent binding is demonstrated. Stable latices with sufficiently high loading of accessible borate anions are prepared via emulsion polymerization. Incorporation of cationic rhodium complexes, supported via their borate counter-anion is efficient, and these supported homogeneous catalysts maintain constant catalytic activity for $\mathrm{C}=\mathrm{C}$ hydrogenation during several recycles, with very low metal leaching.
\end{abstract}

Keywords: catalyst immobilization; counter-anion; emulsion polymerization; polymerizable borate; recycling

A variety of approaches has been demonstrated for the immobilization of homogeneous catalysts, relying nearly exclusively on covalent binding of ligands (such as phosphines) to a particular support. ${ }^{[1]}$ In contrast, anchoring of transition metal compounds via non-covalent binding, e.g., by electrostatic interactions of appropriately substituted mono- or multidentate ligands has attracted relatively little attention to date. ${ }^{[2,3]}$ To avoid even the synthetic challenges associated with the introduction of ionic substituents in (phosphine) ligands, we have investigated the concept of non-covalent binding of a transition metal complex carrying a cationic charge on the metal itself.

We decided to investigate the immobilization, via the counter-anion, of the cationic complexes [Rh(diphosphine)(diene) $] \mathrm{BF}_{4}$, well known precursors for active $\mathrm{C}=\mathrm{C}$ hydrogenation catalysts, ${ }^{[4]}$ on polystyrene-based latices, obtained by emulsion polymerization. ${ }^{[5,6]}$ For this purpose, we introduced the polymerizable triphenylstyrylborate anion, $\left[p-\left(\mathrm{BPh}_{3}\right)\right.$ styrene $\left.^{-},(\mathrm{BS})\right]$ as the potential immobilization site during the emulsion polymerization. The synthesis and copolymerization behavior in emulsions of styryl-functionalized anions and PEO macromonomers such as $\mathrm{CH}_{2}=\mathrm{CHC}_{6} \mathrm{H}_{4} \mathrm{SO}_{3}{ }^{-}$and $\mathrm{CH}_{3} \mathrm{O}-\left(\mathrm{CH}_{2} \mathrm{CH}_{2} \mathrm{O}\right)_{45} \mathrm{CH}_{2} \mathrm{C}_{6} \mathrm{H}_{4} \mathrm{CH}=\mathrm{CH}_{2} \quad\left(\mathrm{C}_{1}\right.$-PEO-VB$45)^{[7]}$ with monomers like styrene have been described in detail by others. ${ }^{[8,9]}$

The air-stable sodium salt NaBS was prepared in a straightforward two-step method, according to modified literature procedures (Scheme 1), by generation of the Grignard reagent ( $p$-styryl) $\mathrm{MgBr}$ and subsequent reaction with one equivalent of triphenylborane.$^{[10]}$

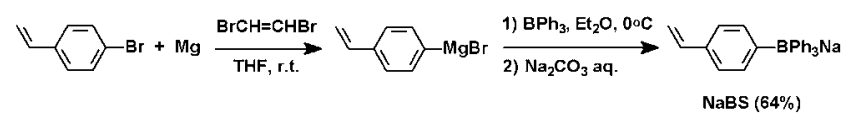

Scheme 1. Synthesis of the sodium salt of the polymerizable borate anion.

'Surfactant-free' emulsion polymerizations of styrene in the presence of various amounts of $\mathrm{NaBS}$, cross-linker divinylbenzene (DVB), and macromonomer $\left(\mathrm{C}_{1}\right.$ - $\mathrm{PEO}-$ VB-45), and with the water-soluble initiator 2,2'azobis[2-methyl- $N$-(2-hydroxyethyl)propionamide] ${ }^{[11]}$ (VA-086) yielded stable and redispersable latices with complete monomer conversion. A purification sequence of filtration, dialysis with cellulose membranes and centrifugation yielded the desired products as white precipitates. Redispersion in water or methanol was possible by ultrasound sonication.

Dynamic light scattering on the dispersions revealed average particle sizes in the range of 90 to $150 \mathrm{~nm}$, which also do not change significantly during centrifugation/ redispersion steps. Particle sizes were confirmed by transmission electron microscopy (TEM), which also demonstrated a reasonably narrow particle size distribu- 
tion (Figure 1). Various anion loadings were used to establish the optimal conditions for cation exchange and stability of latices. As expected, the incorporation of the borate-substituted comonomer (BS) was a prerequisite for obtaining colloidal stable lattices in the 'surfactant-free' emulsion polymerization. When replacing the BS for $\mathrm{NaBPh}_{4}$, only a coagulate was formed. Remarkably, stable lattices were also produced in the absence of additional PEO macromonomer. However, for the introduction of the cationic $\mathrm{Rh}$ complex by cation exchange, the additional steric stabilization provided by the polyethylene glycol moieties proved to be crucial to avoid coagulation.

In order to elucidate the metal immobilization quality by this approach, first catalyst recycling studies were carried out with a non-cross-linked polymer consisting solely of the sodium triphenylstyrylborate (NaBS) and styrene in a ratio of $1: 20$. The reaction between the selected catalyst precursor $[\mathrm{Rh}(\mathrm{dppp})(\mathrm{cod})] \mathrm{BF}_{4}[\mathrm{dppp}=\mathrm{bis}(\mathrm{di}-$ phenylphosphino)propane, $\quad$ cod $=$ cyclooctadiene $]^{[12]}$ and the emulsion was performed in methanol or in a methanol/water mixture. ${ }^{[13]}$ Latices of high borate contents (styrene/NaBS of 20:1) were required to avoid coagulation on incorporation of the $\mathrm{Rh}$ complex. In a typical experiment, a methanol solution of $8.9 \times 10^{-5} \mathrm{~mol}$ $[\mathrm{Rh}(\mathrm{dppp})(\mathrm{cod})] \mathrm{BF}_{4} / \mathrm{g}$ latex (dry solid) was reacted with the emulsion (particle size $135 \mathrm{~nm}$ ). A molar ratio of $1: 4.5$ of $\mathrm{Rh}$ complex and borate groups of the polymer was chosen in order to ensure an excess of tetraphenylborate for efficient ion exchange. After impregnation and coagulation of the emulsion by removal of solvent, the material was extracted three times with methanol. The combined liquids were analyzed for rhodium by inductively coupled plasma (ICP) analysis showing only $2 \%$ of the $\mathrm{Rh}$ remaining in solution. Further extraction did not show any $\mathrm{Rh}$ leaching within the detection limits. In this way $98 \%$ of the initial amount of rhodium had been immobilized, indicating a loading of $c a .25 \%$ of the theoretical latex capacity.

The CP/MAS ${ }^{31} \mathrm{P}$ NMR spectrum of $[\mathrm{Rh}(\mathrm{dppp})$ (cod) $] \mathrm{BS}_{\text {coag }}$ consisted of a broad signal centered around
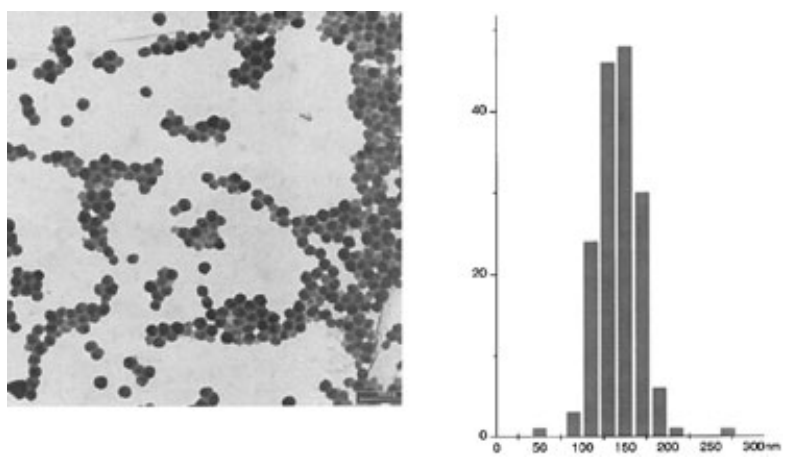

Figure 1. TEM micrograph and histogram of a typical polystyrene latex with both borate- and PEO-substituted comonomers incorporated (S/NaBS/PEO: 120/1/1).
$9 \mathrm{ppm}$, similar to that of $[\mathrm{Rh}(\mathrm{dppp})(\operatorname{cod})] \mathrm{BPh}_{4}$ (sharp signal at $10.7 \mathrm{ppm})$. The polymer sample was too inhomogeneous to obtain the same resolution as for the micro-crystalline benchmark complex. Stirring the precipitated orange $\mathrm{Rh}$-impregnated polymer for $2 \mathrm{~h}$ in methanol under 1.3 bar of $\mathrm{H}_{2}$, followed by filtration, washing and drying under vacuum yielded a yellow solid. The $\mathrm{CP} / \mathrm{MAS}{ }^{31} \mathrm{P}$ NMR spectrum showed a broad resonance at $24 \mathrm{ppm}$, attributed to the catalyst precursor $\left[\mathrm{Rh}(\mathrm{dppp})\left(\eta^{6}-\mathrm{BS}\right)\right]_{\mathrm{coag}}{ }^{[14]}$ along with a weak signal due to traces of unreacted $[\mathrm{Rh}(\mathrm{dppp})(\mathrm{cod})] \mathrm{BS}_{\mathrm{coag}}$.

While the use of latices as such as catalyst supports is also of interest, in the present work only the supporting of the catalyst was performed in emulsion. We chose $\alpha$ acetamidocinnamic acid (ACA) as substrate for a first evaluation of the catalytic performance of the immobilized rhodium precursor $[\mathrm{Rh}(\mathrm{dppp})(\mathrm{cod})] \mathrm{BS}_{\mathrm{coag}}$ in terms of initial activity and recycling stability (Scheme 2).

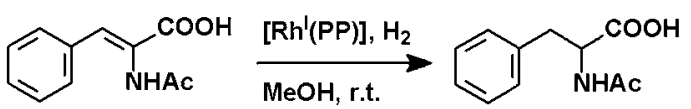

Scheme 2. Rh-catalyzed hydrogenation of $\alpha$-acetamidocinnamic acid.

The hydrogenation reactions were carried out in a filtration cell in the repetitive batch mode, in methanol, with an upward hydrogen flow, similar to a floating bed reactor. The separation of the catalyst from the product was achieved by a simple filtration, before the cell was recharged with a new batch of substrate.

The average initial turnover frequency, based on the initial amount of rhodium added, measured after $15 \mathrm{mi}$ nutes, was about $30 \mathrm{~h}^{-1}$, at which point conversion reached $7 \%$. This activity is about 5 times lower than ob-

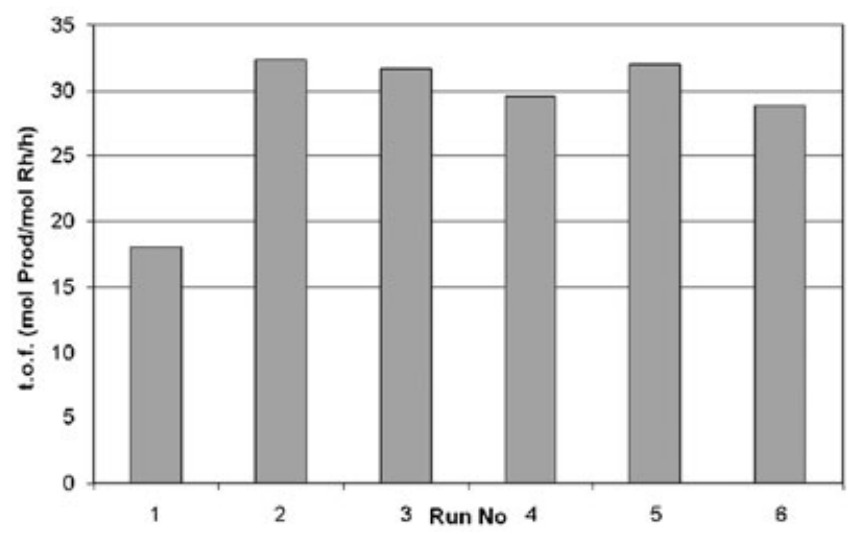

Figure 2. Hydrogenation of $\alpha$-acetamidocinnamic acid (ACA), catalyzed by $[\mathrm{Rh}(\mathrm{dppp})(\operatorname{cod})] \mathrm{BS}_{\mathrm{coag}}$ : activity as a function of catalytic runs. Reaction conditions: $\mathrm{Rh}=$ $0.019 \mathrm{mmol} ; p\left(\mathrm{H}_{2}\right)=1.3 \mathrm{bar}$; solvent $=\mathrm{MeOH}(20 \mathrm{~mL})$; substrate $/ \mathrm{Rh}$ : $100 / 1 ; T=23^{\circ} \mathrm{C}$; reaction times $=15 \mathrm{~min}$. 
served with non-immobilized $[\mathrm{Rh}(\mathrm{dppp})(\mathrm{cod})] \mathrm{BPh}_{4}$ $\left(160 \mathrm{~h}^{-1}\right)$ in a corresponding batch experiment in homogeneous solution. Six cycles were performed without significant loss of activity as shown in Figure 2. The lower TOF observed during the first cycle $\left(20 \mathrm{~h}^{-1}\right)$ was probably due to incomplete activation of the precursor. ICPAAS analysis of the combined product filtrates revealed a total loss of $0.4 \%$ of the total amount of rhodium, corresponding to $<0.07 \%$ average loss per cycle. This initial recycling experiment was repeated twice giving the same results within a margin of $10 \%$.

A batch experiment in a Schlenk tube showed 94\% conversion of the $\alpha$-acetamidocinnamic acid within one hour.

In summary, we have developed a simple and efficient method for the immobilization of catalytically active cationic complexes through non-covalent electrostatic interactions. The catalyst carriers, based on a polymerizable borate anion, are easily obtained by aqueous emulsion polymerization as stable and redispersable polystyrene latices. As a first proof of principle in terms of applicability, we have shown that a rhodium complex supported on coagulated latex has constant catalytic activity in the hydrogenation of a model substrate during several recycles, with very low metal leaching. Future work will focus on asymmetric hydrogenation, exploring the full scope of this approach and on the use of functionalized lattices in continuously operated membrane reactors. ${ }^{[15]}$

\section{Experimental Section}

\section{Typical Latex Preparation}

Sodium triphenylstyrylborate (NaBS; $0.36 \mathrm{~g}, 0.98 \mathrm{mmol}$ ) was dissolved in degassed deionized water $(80 \mathrm{~mL})$. The solution was transferred into a four-neck $250-\mathrm{mL}$ flask equipped with a mechanical stirrer and heated to $80^{\circ} \mathrm{C}$, with a stirring rate of $100 \mathrm{rpm}$. Styrene $(14 \mathrm{~mL}, 122 \mathrm{mmol})$ and a solution of VA086 (0.135 g, $0.5 \mathrm{mmol})$ in water $(14 \mathrm{~mL})$ were then added. The stirring speed was increased to $300 \mathrm{rpm}$. After 15 minutes, the reaction mixture became milky, indicative of the latex formation. The reaction mixture was stirred for 4 hours, during which complete conversion of the monomers occurred as evidenced by analysis of the solids content of periodically withdrawn samples. The latex was cooled to room temperature and purified by dialysis using a benzoylated cellulose membrane during 3-4 days and then centrifuged at 15,000 g. The precipitate was carefully separated from the supernatant and then redispersed in water or methanol by sonication. This operation was repeated twice (particle size $135 \mathrm{~nm}$ ).

\section{$[\mathbf{R h}(\operatorname{dppp})(\mathbf{c o d})] B S_{\text {coag }}$}

$4 \mathrm{~mL}$ of an aqueous NaBS emulsion $\left(3.19 \times 10^{-2} \mathrm{M}, 1.28 \times 10^{-1}\right.$ mmol borate, 4.5 equivs.) were added to a solution of $[\mathrm{Rh}(\mathrm{dppp})(\mathrm{cod})] \mathrm{BF}_{4}\left(20.3 \mathrm{mg}, 2.86 \times 10^{-2} \mathrm{mmol}\right)$ in methanol
(20 mL). A ratio of borate-containing latex and $\mathrm{Rh}$ complex of 4.5 was chosen to ensure an excess of borate for efficient exchange. The reaction mixture was stirred for $30 \mathrm{~min}$ and the volatiles removed under vacuum, affording a yellow/orange solid, which was dried azeotropically with toluene (twice $10 \mathrm{~mL}$ ) and washed with methanol $(3 \times 10 \mathrm{~mL})$. CP/MAS ${ }^{31} \mathrm{P}$ NMR (109.4 MHz): $\delta=8.5 \mathrm{ppm}\left(\mathrm{s}\right.$ br, $\mathrm{w}_{1 / 2}=965 \mathrm{~Hz}$ ). The combined methanol extracts were analyzed for rhodium by ICP-AAS indicating that $98 \%$ of the rhodium had been immobilized, corresponding to $25 \%$ loading of the borate in the polymer (based on the initial amount of BS in the copolymerization).

\section{Hydrogenation Reaction}

The polystyrene-supported catalyst precursor $(0.019 \mathrm{mmol}$ of $\mathrm{Rh}$ ) was placed in a glass custom-made filtration cell equipped with a G4 frit, in methanol suspension $(20 \mathrm{~mL})$. Hydrogen (1.3 bar) was bubbled through the suspension for $2 \mathrm{~h}$. The solvent was expelled from the cell and replaced by a solution of substrate $\alpha$-acetamidocinnamic acid $(1.9 \mathrm{mmol})$ in methanol. After 15 minutes, the reaction mixture was filtered through the frit and the filtrate analyzed by GC. The solid catalyst left in the cell was re-used for several runs. The filtrates were combined, dried under vacuum, and the residue analyzed for $\mathrm{Rh}$ content by ICP-AAS.

\section{Acknowledgements}

R. S. thanks the National Research School Combination - Catalysis (NRSCC) for a fellowship. We thank Dr. Magusin (TU/e) for CP-MAS NMR measurements. A sample of C1PEO-H-45 by Dr F. Reichel (Goldschmidt AG, Essen) as well as a generous loan of noble metals by Umicore $A G \& C o . K G$ are gratefully acknowledged.

\section{References and Notes}

[1] For recent reviews on recoverable catalysts and reagents, see: Chem. Rev. 2002, 102, 3215-3892 (special issue on catalyst immobilization).

[2] Immobilization on ion-exchange resins: S. C. Tang, T. E. Paxson, T. E.; L. Kim, J. Mol. Catal. 1980, 9, 313; R. T. Smith, R. K. Ungar, M. C. Baird, Transition Met. Chem. 1982, 7, 288; I. Toth, B. E. Hanson, I. Guo, M. E. Davis, Catal. Lett. 1991, 8, 20; H. Turk, W. T. Ford, J. Org. Chem. 1991, 56, 1253; immobilization on a polyacid: R. Augustine, S. Tanielyan, S. Anderson, H. Yang, Chem. Commun. 1999, 1257.

[3] E. Schwab, S. Mecking, Organometallics 2001, 20, 5504; R. van de Coevering, M. Kuil, R. J. M. Klein Gebbink, G. van Koten, Chem. Commun. 2002, 1636; R. Akiyama, S. Kobayashi, Angew. Chem. Int. Ed. 2002, 41, 2602; S. Mecking, R. Thomann, Adv. Mater. 2000, 12, 953; F. M. de Rege, D. K. Morita, K. C. Ott, W. Tumas, R. D. Broene, Chem. Commun. 2000, 1797.

[4] H. B. Kagan, T.-P. Dang, J. Am. Chem. Soc. 1972, 94, 6429. 
[5] Polymer latices, that is colloidally stable dispersions of submicron polymer particles in a liquid medium, usually water, can be readily obtained by emulsion polymerization, including mini- and microemulsion polymerisation. ${ }^{[6]}$ The latices cover a wide range of accessible particle sizes (ca. 10-1000 $\mathrm{nm}$ in diameter), and they can be prepared with narrow particle size distributions. Their easily accessible large outer surface (for ideal spheres of $\varnothing 200 \mathrm{~nm} c a .30 \mathrm{~m}^{2} / \mathrm{g}$ solids) enables facile reactions on the particle surface.

[6] Emulsion Polymerization and Emulsion Polymers, (Eds.: P. A. Lovell, M. S. El-Aasser), Wiley, Chichester, 1997; W. T. Ford, React. Funct. Polym. 1997, 33, 147.

[7] K. Ito, S. Yokohama, F. Arakawa, Y. Yukawa, T. Iwashita, Y. Yamasaki, Y. Polym. Bull. 1986, 16, 337.

[8] J. H. Kim, M. Chainey. M. S. El-Aasser, J. W. Vanderhoff, J. Polym. Sci. A: Polym. Chem. 1992, 30, 171; J. M. PeulaGarcia, R. Hidalgo-Alvarez, F. J. de las Nieves, Colloids and Surfaces A: Physicochem. Eng. Aspects 1997, 127, 19.

[9] M. Maniruzzaman, S. Kawagushi, K. Ito, Macromolecules 2000, 33, 1583; K. Ito, Prog. Polym. Sci. 1998, 23, 581; K. Ito, S. Kawagushi, Adv. Polym. Sci. 1999, 142,
129; A. Tuncel, E. Serpen, Colloid Polym. Sci. 2001, 279, 240; J. S. Shay, R. J. English, R. J. Spontak, C. M. Balik, S. A. Khan, Macromolecules 2000, 33, 6664.

[10] M. Ono, S. Hinokuma, S. Miyake, S. Inazawa, (Japan Polyolefins Co., Ltd.), Eur. Patent Appl. 710,663, 1996; Chem. Abstr. 1996, 125, 87466.

[11] VA-086 (purchased from Wako) was chosen as a non-coordinating, non-ionic and high temperature water-soluble azo initiator ( 10 hour half-life temperature: $\left.86^{\circ} \mathrm{C}\right)$.

[12] J. Bakos, I., Tóth, Heil, G. Szalontai, G.; L. Párkányi, V. Fülöp, J. Organomet. Chem. 1989, 370, 263.

[13] Under identical conditions, the reaction between $[\mathrm{Rh}(\mathrm{dppp})(\mathrm{cod})] \mathrm{BF}_{4}$ and an excess of $\mathrm{NaBPh}_{4}$ quantitatively generated $[\mathrm{Rh}(\mathrm{dppp})(\mathrm{cod})] \mathrm{BPh}_{4}$.

[14] J. M. Brown, P. A. Chaloner, A. G. Kent, B. A. Murrer, P. N. Nicholson, D. Parker, P. J. Sidebottom, J. Organomet. Chem. 1981, 216, 263; B. Longato, G. Pilloni, R. Graziani, U. Casellato, J. Organomet. Chem. 1991, 407, 369.

[15] R. Sablong, U. Schlotterbeck, S. Mecking, D. Vogt, $A d v$. Synth. Catal. 2003, 345, 333. 